\title{
Community-based interventions for childhood asthma using comprehensive approaches: a systematic review and meta-analysis
}

Mei Chan ${ }^{1}$ (), Melinda Gray², Christine Burns², Louisa Owens ${ }^{1,2}$, Susan Woolfenden ${ }^{1,2}$, Raghu Lingam,2, Adam Jaffe ${ }^{1,2}$ and Nusrat Homaira ${ }^{1,2^{*}}$

\begin{abstract}
Objective: We conducted a systematic review and meta-analysis to determine the effectiveness of comprehensive community-based interventions with $\geq 2$ components in improving asthma outcomes in children.

Methods: A systematic search of Medline, Cumulative Index to Nursing and Allied Health Literature (CINAHL), Excerpta Medica Database (EMBASE), Cochrane Library and hand search of reference collections were conducted to identify any research articles published in English between 2000 and 2019. All studies reporting communitybased asthma interventions with $\geq 2$ components (e.g., asthma self-management education, home environmental assessment or care coordination etc.) for children aged $\leq 18$ years were included. Meta-analyses were performed using random-effects model to estimate pooled odds ratio (OR) with 95\% confidence intervals (Cls).

Results: Of the 2352 studies identified, 21 studies were included in the final analysis: 19 pre-post interventions, one randomised controlled trial (RCT) and one retrospective study. Comprehensive asthma programs with multicomponent interventions were associated with significant reduction in asthma-related Emergency Department $(E D)$ visits ( $O R=0.26 ; 95 \% \mathrm{Cl} 0.20-0.35$ ), hospitalizations ( $\mathrm{OR}=0.24 ; 95 \% \mathrm{Cl} 0.15-0.38$ ), number of days (mean difference $=-2.58 ; 95 \% \mathrm{Cl}-3.00$ to -2.17 ) and nights with asthma symptoms (mean difference $=-2.14 ; 95 \% \mathrm{Cl}$ -2.94 to -1.34$)$, use of short-acting asthma medications/bronchodilators (BD) $(\mathrm{OR}=0.28 ; 95 \% \mathrm{Cl} 0.16-0.51)$, and increase use of asthma action plan (AAP) (OR $=8.87 ; 95 \% \mathrm{Cl} 3.85-20.45)$.
\end{abstract}

Conclusion: Community-based asthma care using more comprehensive approaches may improve childhood asthma management and reduce asthma related health care utilization.

Keywords: Community-based, Meta-analysis, Asthma, Childhood, Comprehensive intervention

*Correspondence: n.homaira@unsw.edu.au

${ }^{1}$ Discipline of Paediatrics, School of Women's and Children's Health,

Faculty of Medicine, University of New South Wales, Sydney, NSW 2031, Australia

Full list of author information is available at the end of the article

\section{Background}

Asthma is a significant public health problem affecting 339 million people worldwide [1]. According to the Global Asthma Report [1], it is the 16th leading cause of disability adjusted life years lost (DALYs) and 28th leading cause of burden of disease.

Despite advancement in understanding of the disease and availability of effective treatments, asthma remains one of the most common causes of preventable visits

(c) The Author(s) 2021. This article is licensed under a Creative Commons Attribution 4.0 International License, which permits use, sharing, adaptation, distribution and reproduction in any medium or format, as long as you give appropriate credit to the original author(s) and the source, provide a link to the Creative Commons licence, and indicate if changes were made. The images or other third party material in this article are included in the article's Creative Commons licence, unless indicated otherwise in a credit line to the material. If material is not included in the article's Creative Commons licence and your intended use is not permitted by statutory regulation or exceeds the permitted use, you will need to obtain permission directly from the copyright holder. To view a copy of this licence, visit http://creativeco mmons.org/licenses/by/4.0/. The Creative Commons Public Domain Dedication waiver (http://creativecommons.org/publicdomain/ zero/1.0/) applies to the data made available in this article, unless otherwise stated in a credit line to the data. 
to emergency department (ED) and admissions to hospital in children [2]. The reasons for poor progress in pediatric asthma control are multifaceted, including difficulties with medication adherence, inadequate asthma education, failure to mitigate environmental triggers, lack of coordination within and between healthcare services etc. [3]. As the roots of these problems often lie outside the acute care system, there is growing interest in developing and implementing an effective community-based approach to improve asthma-related health outcomes in children.

The majority of community-based programs developed in the last decades to improve childhood asthma strategies have mainly focused on single intervention comprising asthma self-management education for the child/caregivers involving only one community settings e.g., school or home. However, reports on the effectiveness of such interventions have not been consistent [4]. In a meta-analysis of 37 studies, it was found that although asthma education alone had significantly reduced the odds of ED visits for asthma, the impact on hospital admissions and urgent physician visits were not significant [4]. This is most likely because asthma is a complex disease with a broad range of contributing factors which are not limited to the physiological, but also include environmental, social and behavioural determinants of health. Therefore, a combination of interventions that address the social behavioural and physiological aspect of asthma through bridging the gap between hospital- and community-based services are necessary to achieve better health outcomes for children with asthma. Comprehensive asthma programs with multicomponent interventions that include selfmanagement skills, environmental triggers avoidance, care coordination, advocacy for community or governmental support etc., and various members of the community e.g., schools, neighbourhood, government/policy makers etc., have been developed and implemented. However, a critical review of recent evidence and effort to quantify the effectiveness of these more comprehensive community-based approaches which interconnect different stakeholders is lacking.

\section{Objectives}

The objectives of this systematic review were to systematically evaluate the existing body of evidence to identify the key components of multicomponent interventions and determine their effectiveness in improving health outcomes in children with asthma.

\section{Methods}

This systematic review adopted the Preferred Reporting Items for Systematic Reviews and Meta-analyses (PRISMA) standards (Prospero registration number: CRD 42019133776).

\section{Types of studies}

We included randomized clinical trials (RCTs) and quasi-experimental studies (i.e., pre- and postintervention studies, retrospective cohort studies) in this review.

\section{Types of participants}

Only studies including children aged $\leq 18$ years, who have been diagnosed with asthma or shown symptoms of asthma, and participated in a communitybased asthma program with multiple intervention components were considered in this review.

\section{Types of interventions}

Studies selected involved comparison of communitybased interventions with $\geq 2$ components that aimed to improve health outcomes or management pathways versus no intervention for children with asthma. The interventions could have taken place in a variety of community settings e.g., homes, community health clinics, schools etc., and carried out by any health care professionals (e.g., nurses, asthma educators, social workers or community health workers etc.). Interventions included (A) asthma self-management education, (B) home environmental assessment (i.e. home visits for trigger assessments with or without remediation supplies), (C) care coordination (i.e., connecting patients/families with relevant health care or social services), (D) school involvement (e.g. asthma education for patients or school personnel, behavioural counselling at school etc.), (E) involvement of primary healthcare providers for ongoing asthma assessment, provision of AAP etc., (F) community involvement (e.g. awareness campaign, neighbourhood support etc.) or (G) advocacy for government/local organization involvement in policy changes.

\section{Types of outcome measures}

Outcomes of interest included differences between those with and without intervention in (1) acute care utilization e.g., ED visits and hospitalization, (2) asthma control e.g., asthma symptom day/night, use of asthma action plan (AAP), asthma medication uses or Asthma Control Test (ACT) score, (3) pulmonary function e.g., forced expiratory volume in one second $\left(\mathrm{FEV}_{1}\right)$, and (4) productivity e.g., school or work absenteeism. 
Qualitative/narrative data collected from interviews or open questions were not analyzed.

\section{Search methods for identification of studies}

Eligible articles were identified from four electronic databases: Medline, Cumulative Index to Nursing and Allied Health Literature (CINAHL), Excerpta Medica Database (EMBASE) and Cochrane Library. Additional studies were retrieved from the reference lists of identified articles. Original articles published between 2000 and 2019 were searched using a combination of MeSH keywords: (1) "asthma"; (2) "child" or "pediatrics" or "childhood", "child health"; (3) "community" or "community care" or "community health service", "public health", "multicomponent", “integrated care”, "comprehensive", "collaborative", "care coordination". Studies were included if they were: (1) published in English language, (2) available in full-text, (3) conducted in humans, (4) conducted in children with asthma, (5) involving community-based interventions. Studies were excluded if they were: (1) review articles, (2) unpublished data, or (3) qualitative/narrative research studies.

\section{Study selection process}

Figure 1 summarizes details of the study selection process. All articles identified through database searches were screened for duplication, full text availability and language used. Titles and abstracts of the remaining

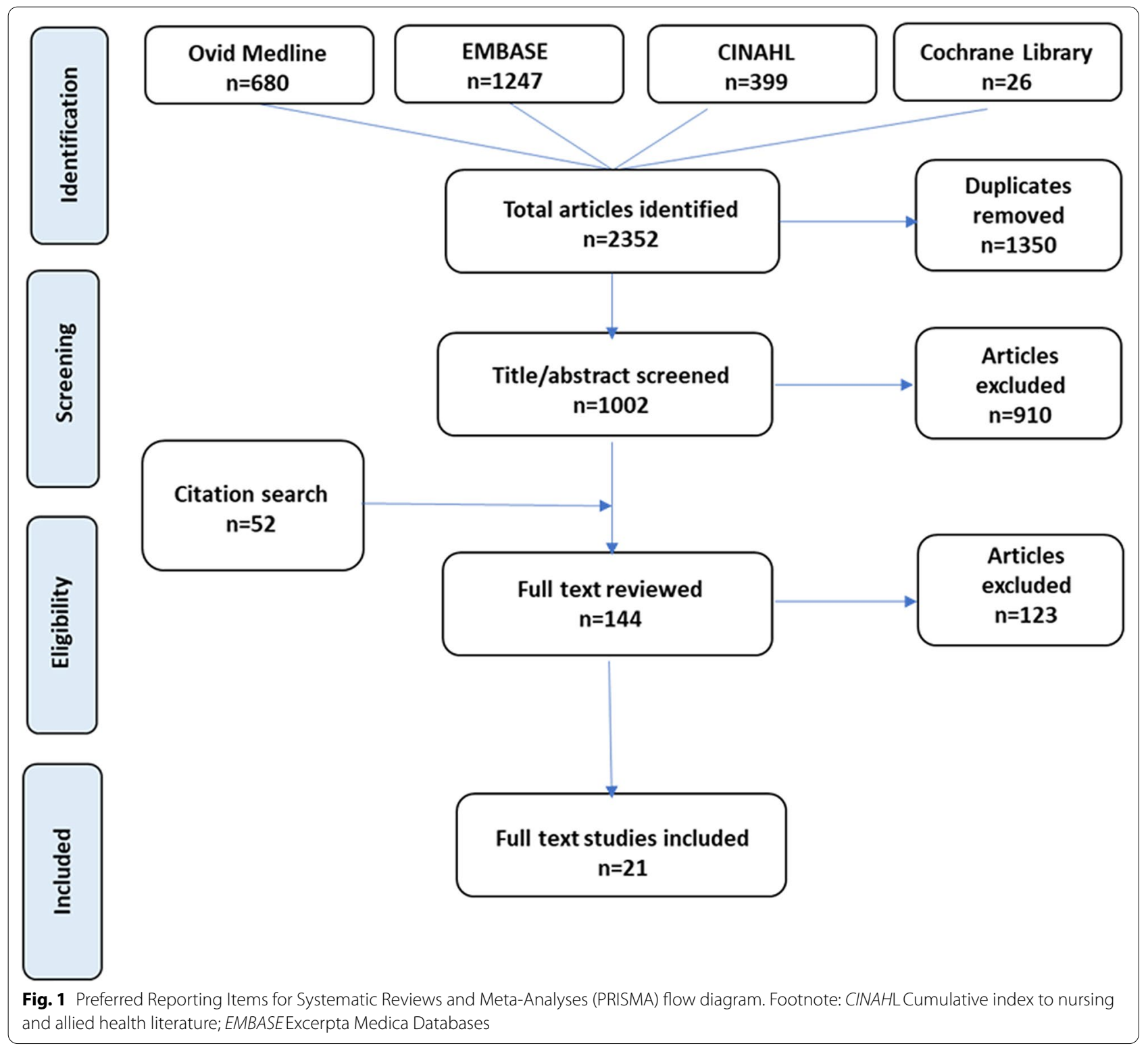


articles were reviewed for eligibility by one reviewer. Studies with titles or abstracts that met the inclusion criteria had full-text review. A research team member assessed the contents of the articles to determine whether they were to be included in this review and final decision was reached after agreement was obtained from the principal investigator.

\section{Data extraction and quality assessment}

The following data were extracted from the selected studies and entered into a table developed by the research team: authors, year of study, study duration, study design, sample size, age, care provider, ethnicity, asthma severity, intervention components and key findings. Accuracy and completeness of the data were counter checked by the second reviewer.

The strength and quality of the studies was assessed by using the Risk of Bias In Non-randomized Studies (ROBINS-I) tool developed by the Cochrane Bias Method Group [5]. The strength of the evidence was assessed based on seven domains: (1) bias due to confounding, (2) bias in selection of participants into the study, (3) bias in classification of interventions, (4) bias due to deviations from intended interventions, (5) bias due to missing data, (6) bias in measurement of outcomes, (7) bias in selection of the reported result [5].

\section{Data analysis}

Meta-analyses were performed to pool data from studies with sufficient information of the same outcome measures. Dichotomous data were analyzed using odds ratio (OR) and continuous outcomes were analyzed using weighted mean difference (MD). DerSimonian and Laird's random effects model was used to estimate the overall effect size with $95 \%$ confidence interval (CI). For data that were unavailable or could not be extracted from information provided, the authors of the studies were contacted to obtain the relevant information. For continuous data, missing standard deviations were estimated from other summary statistics (e.g., confidence intervals, standard errors, $t$ values or $p$ values) using the methods described by Higgins and Green [6].

Standard chi-squared $\left(X^{2}\right)$ test and $I^{2}$ statistics was calculated to evaluate the level of heterogeneity of the pooled results (i.e., whether the variance was genuine or due to sampling error), and considerable heterogeneity was present if $I^{2} \geq 75 \%$ and $X^{2} \leq 0.1$ [7]. Sensitivity analysis was conducted using stepwise single-study elimination method to determine if our decision had any impact on the pooled results by omitting each study. All statistical analyses were carried out using Review Manager (RevMan) software version 5.3 [8].

\section{Results}

\section{Results of the search}

A total of 2352 potential articles were identified from the initial literature search. After duplicates were removed, titles/abstracts of 1,002 articles were screened for eligibility and full text availability. Of these, 92 articles, together with the 52 articles retrieved from the reference lists, underwent full text review. As a result, a total of 21 studies met the selection criteria and were included in this systematic review. Details of the search strategy is depicted by a PRISMA flow chart in Fig. 1 .

\section{Study characteristics}

Among the 21 studies, nineteen were pre-post intervention studies [9-27], one was RCT [28] and one was retrospective cohort [29] study. Overall, risk of bias was moderate as illustrated in Fig. 2. All of the studies were carried out in the United States (US), except one in Australia [10]. Ethnic minorities (i.e. African American and Hispanic American) were the focus in 18 of the 20 studies [9, 11, 12, 14-18, 20-29]. Sample sizes varied widely ranging from 65 to 134,480 children $($ median $=295)$ aged from $0-18$ years $($ Table 1$)$. Interventions were delivered mainly by nurses including asthma educators, nurse practitioners etc. (13/21), [9$14,16,18-20,22,23,25]$ followed by community health workers $(11 / 21),[12,14-17,20-22,25,27,29]$ social workers $(4 / 21),[11,13,24,28]$ physicians $(3 / 21),[11,22$, $25]$ respiratory therapists $(2 / 21),[13,15]$ psychologists $(1 / 21)$, [28] pharmacist $(1 / 21)$ [13].

As shown in Table 1, intervention components of each programs were different. However, education on basic asthma knowledge and self-management skills, care coordination to connect patients/families with relevant primary care or social services, and home visit for environmental trigger assessment were common intervention elements (i.e., core interventions) across 20 of 21 reviewed studies. Other interventions such as provision of environmental remediation products e.g. allergen-proof beddings and pillow encasings, cleaning supplies, cockroach abatement etc. were employed in 13 studies [9, 11-14, 16-21, 26, 27]. Engagement with schools to increase asthma awareness, provide asthma education to staff members, promote asthma-friendly school environment or improve communication between care providers and schools, were parts of the intervention programs in 13 of the 21 studies [1113, 15-17, 20-22, 24, 26, 28, 29]. Fourteen studies [10-13, 15-18, 20-22, 25, 26, 29] also worked with primary care providers to address issues of healthcare accessibility, inform of patient's progress, perform medical assessment, medication adjustment, review 


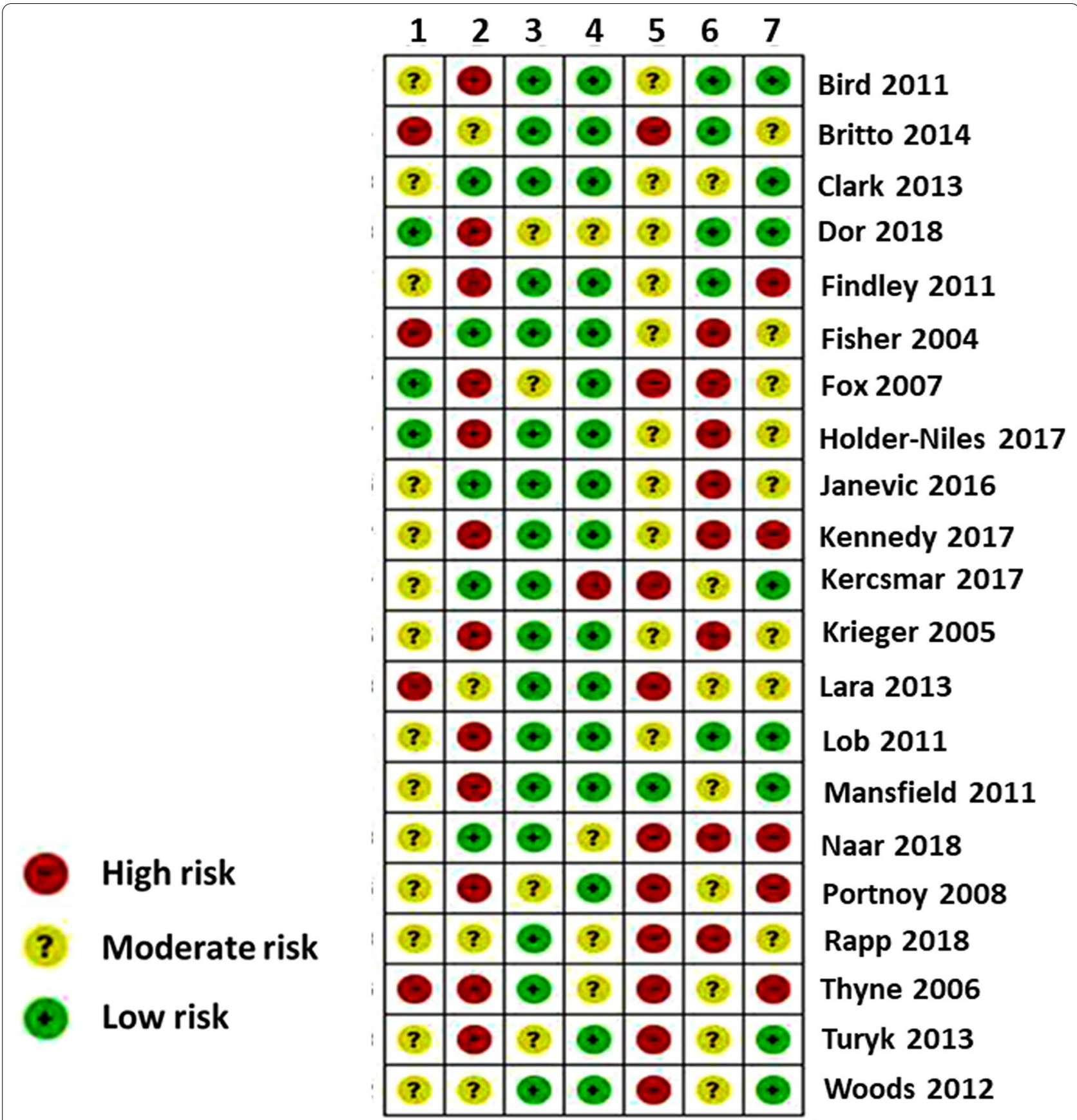

Fig. 2 Summary of risk of bias of included studies. Legends: $1=$ Bias due to confounding. $2=$ Bias in selection of participants into the study. $3=$ Bias in classification of interventions. $4=$ Bias due to deviations from intended interventions. $5=$ Bias due to missing data. $6=$ Bias in measurement of outcomes. $7=$ Bias in selection of the reported result

of AAPs, or update with practice change and latest asthma guidelines. Whereas, in 14 studies, [12, 1518, 20-27, 29] effort was made through community fairs or education sessions to increase community awareness and social support for children with asthma.
Additionally, public or community organizations/ agencies were involved in 14 studies [12, 13, 15-18, 20-23, 25-27, 29] to bring about changes in clinical or community systems to ensure more effective disease management. 


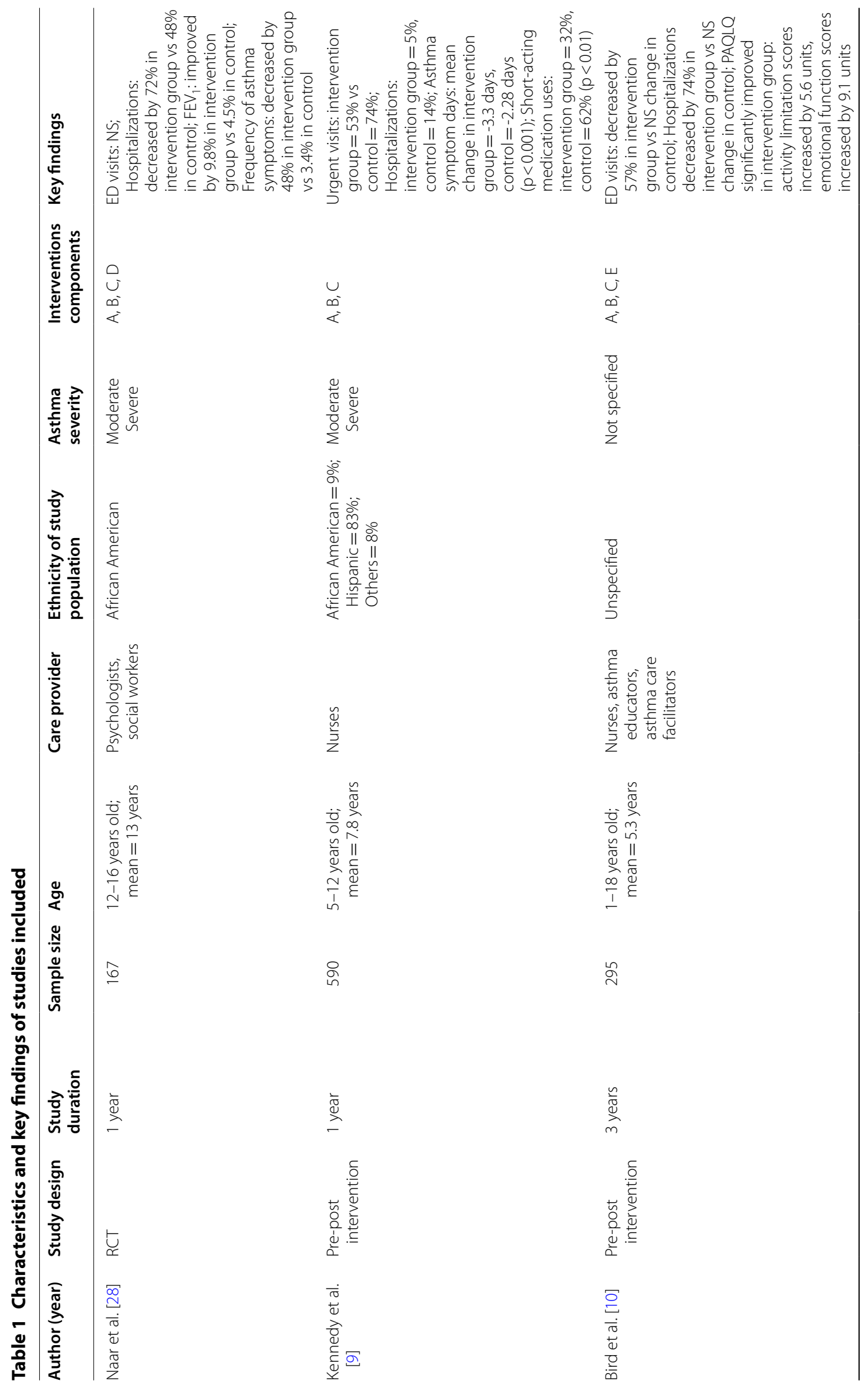




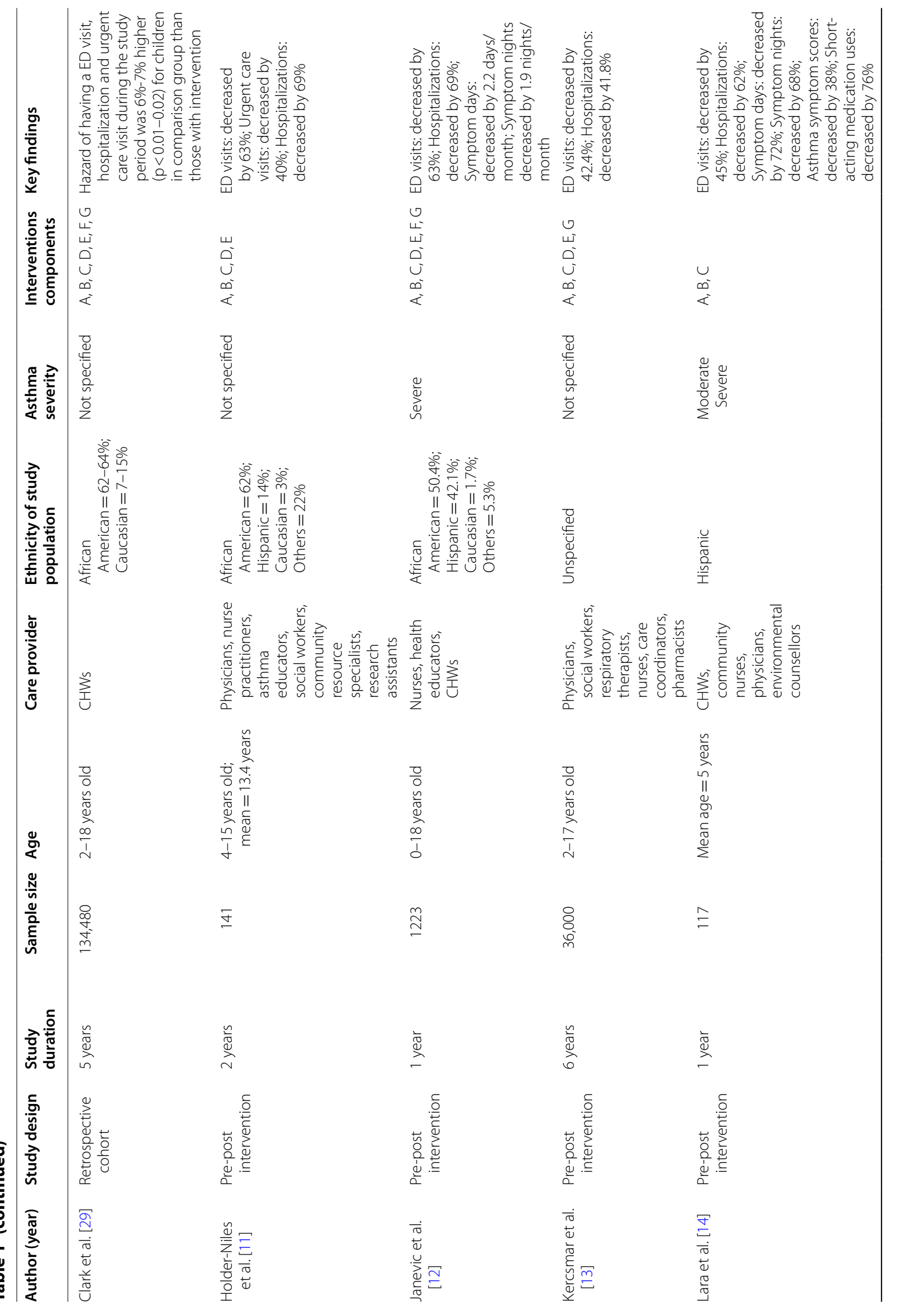




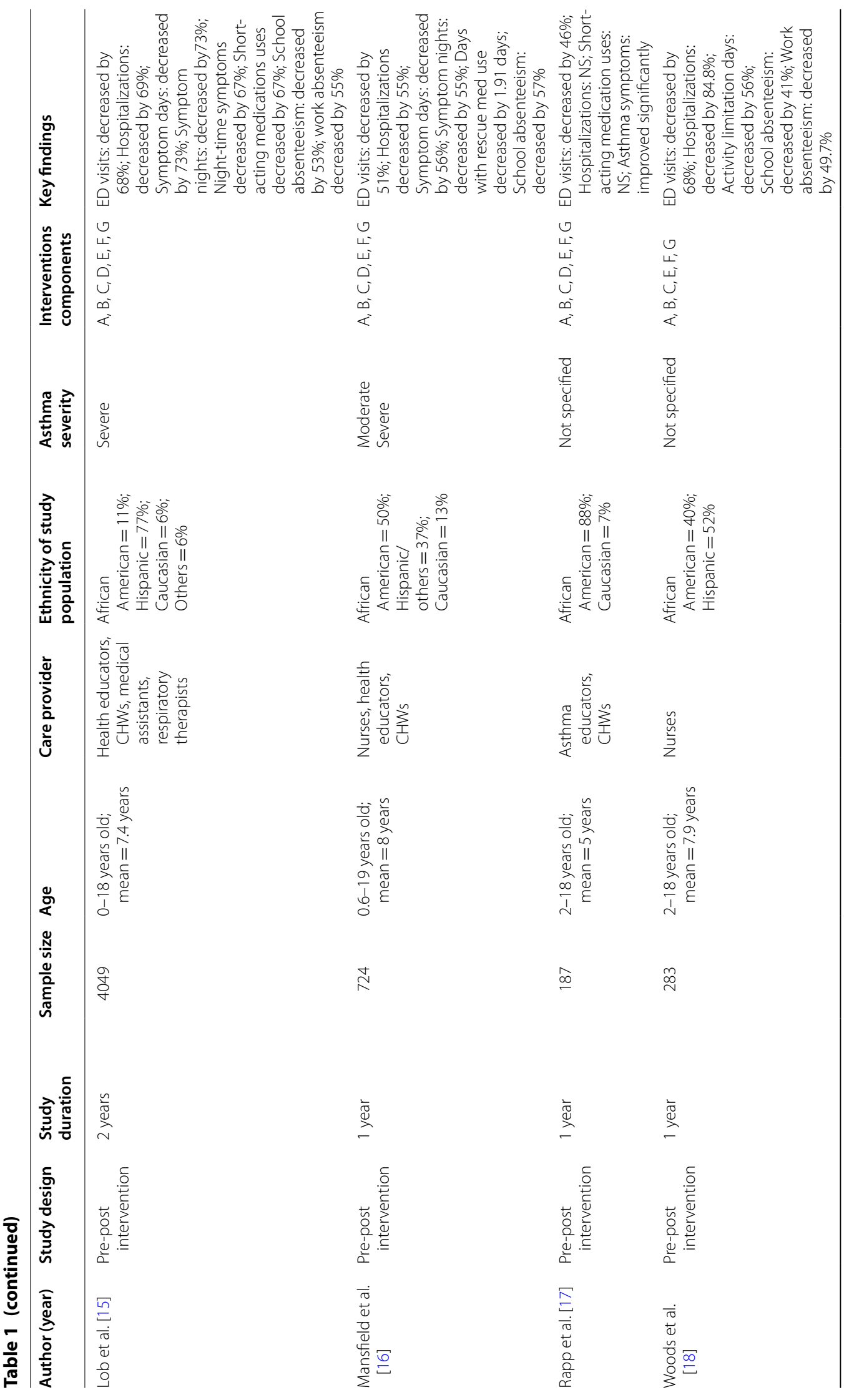




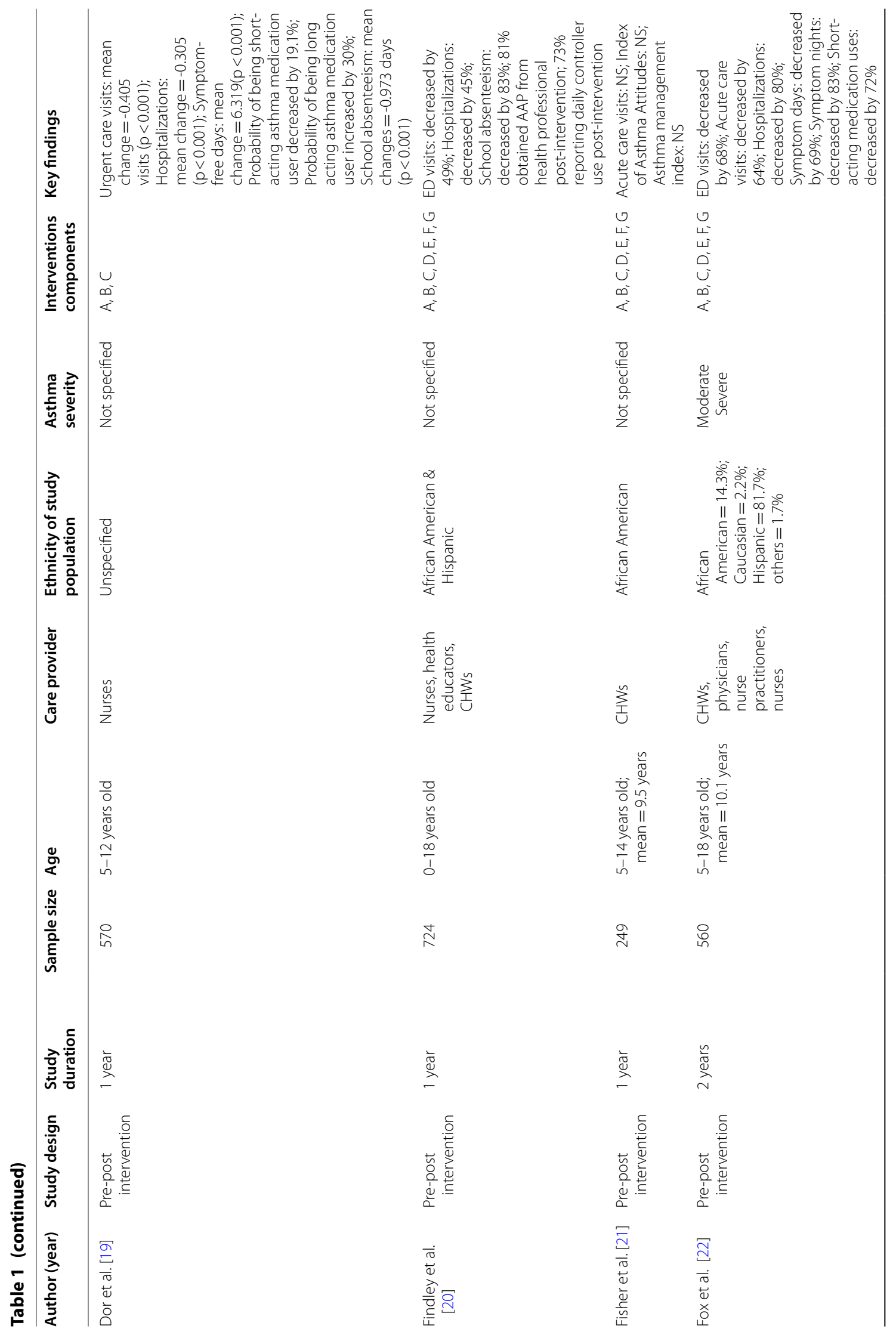




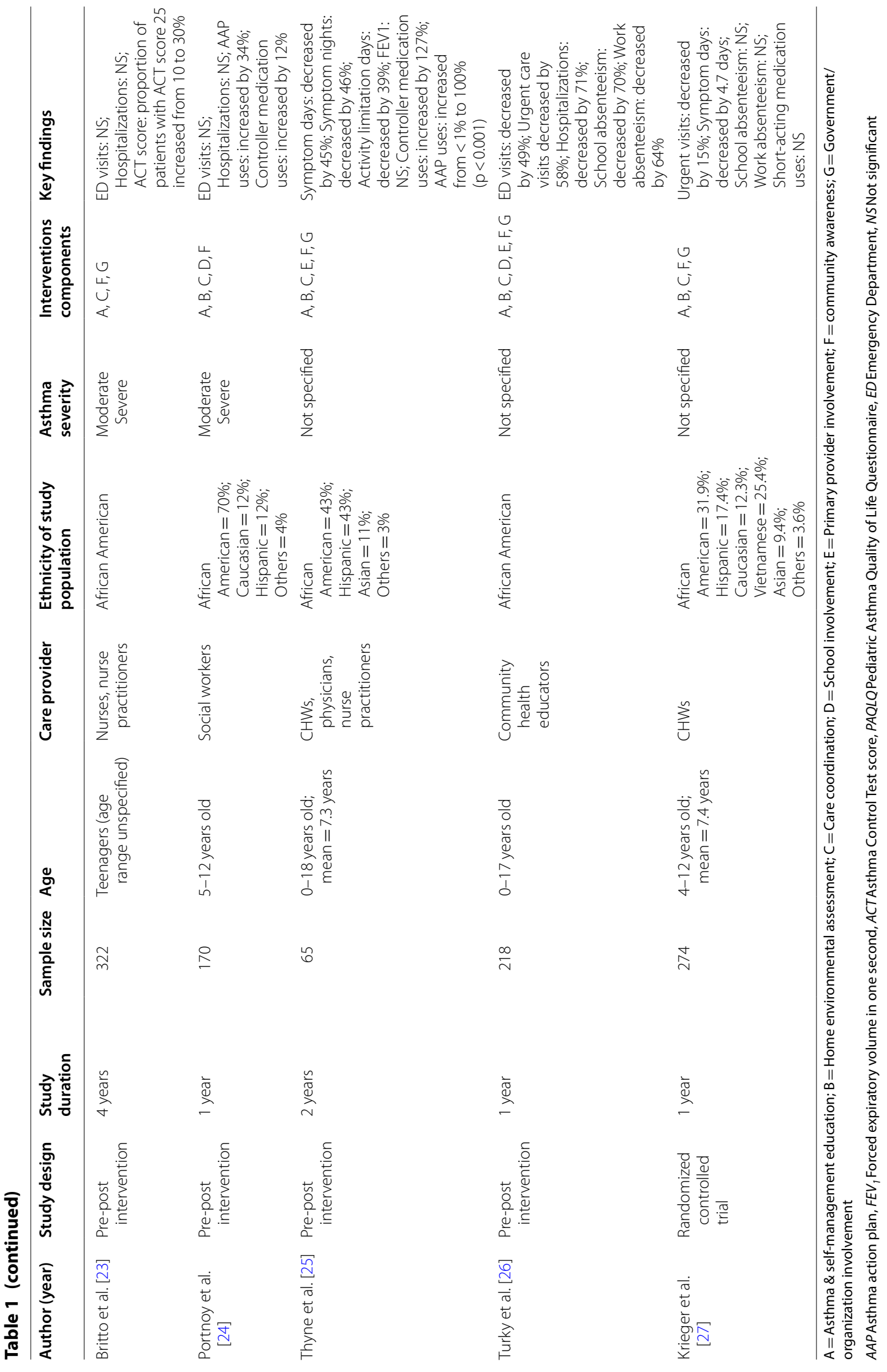


Effect of interventions on health care utilizations

Overall, ED visits were evaluated in 16 studies, [10-18, $20,22-24,26,28,29]$ of which, 13 reported a significant post-intervention reduction in asthma-related ED visits [10-18, 20, 22, 26, 29] (Table 1). Among these 13 studies, eight presented complete dichotomous data on ED visits (yes/no). Meta-analysis of these studies revealed that ED visits were significantly reduced after multicomponent community-based interventions $(\mathrm{OR}=0.26$; 95\% CI 0.20-0.35) (Fig. 3).

Multicomponent interventions were also associated with reduction in asthma-related hospitalizations in 15 [9-16, 18-20, 22, 26, 28, 29] of 18 studies [9-20, $22-24,26,28,29]$ that reported the outcome measure (Table 1). The odds of asthma-related hospitalization was reduced by $76 \%$ in children with vs without interventions ( $\mathrm{OR}=0.24 ; 95 \%$ CI 0.15-0.38) (Fig. 4).

\section{Effects on asthma control}

Ten studies measured changes in asthma symptoms from pre- to post-implementation of intervention programs $[9,12,14-17,19,22,25,28]$. All 10 studies reported a beneficial effect of intervention with significant decrease in days with asthma symptoms, while six of the studies [12, 14-16, 22, 25] also reported decrease in nights with asthma symptoms (Table 1). The pooled intervention effects, in terms of mean differences (MDs), were -2.58 days per fortnight $(95 \% \mathrm{CI}-3.00,-2.17)$ (Fig. 5) and -2.14 nights per fortnight $(95 \%$ CI $-2.94,-1.34)$ (Fig. 6) with asthma symptoms based on data available in three studies. [12, 16, 25]

Two studies $[25,28]$ measured lung function of the study population, in terms of $\mathrm{FEV}_{1}$, however, only one of them [28] reported significant improvement of $15.6 \%$ (i.e., from 2.05 at baseline to 2.31 at 12 months; $p<0.001)$. One study assessed ACT score and reported an increase in the proportion of patients with optimally

\begin{tabular}{|c|c|c|c|c|c|c|c|c|}
\hline \multirow{2}{*}{$\begin{array}{l}\text { Study } \\
\text { Findley } 2011\end{array}$} & \multicolumn{2}{|c|}{ Intervention } & \multicolumn{2}{|c|}{ Nointervention } & Weight & $\begin{array}{c}\text { Odds Ratio } \\
\text { M-H, Random, } 95 \% \mathrm{Cl}\end{array}$ & \multicolumn{2}{|c|}{$\begin{array}{c}\text { Odds Ratio } \\
\text { M-H, Random, } 95 \% \mathrm{Cl}\end{array}$} \\
\hline & 108 & 724 & 211 & 724 & $14.2 \%$ & $0.43[0.33,0.55]$ & $\rightarrow$ & \\
\hline Fox 2007 & 24 & 280 & 75 & 280 & $11.0 \%$ & $0.26[0.16,0.42]$ & & \\
\hline Lara 2013 & 53 & 117 & 119 & 145 & $10.1 \%$ & $0.18[0.10,0.32]$ & 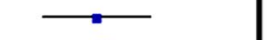 & \\
\hline Lob 2011 & 57 & 761 & 225 & 761 & $13.6 \%$ & $0.19[0.14,0.26]$ & & \\
\hline Mansfield 2011 & 210 & 720 & 428 & 723 & $14.7 \%$ & $0.28[0.23,0.35]$ & $\rightarrow$ & \\
\hline Rapp 2018 & 41 & 187 & 77 & 187 & $11.6 \%$ & $0.40[0.26,0.63]$ & -- & \\
\hline Turyk 2013 & 52 & 218 & 102 & 218 & $12.2 \%$ & $0.36[0.24,0.54]$ & $\rightarrow$ & \\
\hline Woods 2012 & 62 & 283 & 194 & 283 & $12.7 \%$ & $0.13[0.09,0.19]$ & & \\
\hline Total $(95 \% \mathrm{Cl})$ & & 3290 & & 3321 & $100.0 \%$ & $0.26[0.20,0.35]$ & & \\
\hline Total events & 607 & & 1431 & & & & & \\
\hline $\begin{array}{l}\text { Heterogeneity: T } \\
\text { Test for overall } \mathrm{e}\end{array}$ & $\begin{array}{l}0.14 ; \mathrm{Chi}^{2}= \\
Z=9.03(\mathrm{P}\end{array}$ & $\begin{array}{l}=38.00 \\
<0.00\end{array}$ & $\begin{array}{l}\mathrm{df}=7(\mathrm{P}<0 \\
001)\end{array}$ & 0.00001 & 1); $I^{2}=82 \%$ & & $\begin{array}{ccc}1 & 1 & 1 \\
0.1 & 0.2 & 0.5 \\
\text { Favours intervention }\end{array}$ & $\begin{array}{cccc}1 & 2 & 5 & 10 \\
\text { Favours no intervention }\end{array}$ \\
\hline
\end{tabular}

\begin{tabular}{|c|c|c|c|c|c|c|c|c|}
\hline \multirow{2}{*}{$\frac{\text { Study }}{\text { Findley } 2011}$} & \multicolumn{2}{|c|}{$\begin{array}{c}\text { Intervention } \\
\text { Hospitalization Total }\end{array}$} & \multicolumn{2}{|c|}{$\begin{array}{l}\text { Nointervention } \\
\text { Hospitalization Total }\end{array}$} & \multirow{2}{*}{$\begin{array}{l}\text { Weight } \\
12.9 \%\end{array}$} & \multirow{2}{*}{$\begin{array}{l}\begin{array}{c}\text { Odds Ratio } \\
\text { M-H, Random, } 95 \% \mathrm{Cl}\end{array} \\
0.52[0.36,0.75]\end{array}$} & \multicolumn{2}{|c|}{$\begin{array}{c}\text { Odds Ratio } \\
\mathrm{M}-\mathrm{H}, \text { Random, } 95 \% \mathrm{Cl}\end{array}$} \\
\hline & 47 & 724 & 86 & 724 & & & - & \\
\hline Fox 2007 & 5 & 280 & 24 & 280 & $8.5 \%$ & $0.19[0.07,0.52]$ & & \\
\hline Kennedy 2017 & 16 & 314 & 63 & 314 & $11.5 \%$ & $0.21[0.12,0.38]$ & & \\
\hline Lara 2013 & 16 & 117 & 52 & 145 & $11.1 \%$ & $0.28[0.15,0.53]$ & & \\
\hline Lob 2011 & 10 & 761 & 83 & 761 & $10.8 \%$ & $0.11[0.06,0.21]$ & & \\
\hline Mansfield 2011 & 82 & 720 & 184 & 723 & $13.3 \%$ & $0.38[0.28,0.50]$ & $\rightarrow-$ & \\
\hline Rapp 2018 & 9 & 187 & 19 & 187 & $9.6 \%$ & $0.45[0.20,1.02]$ & & \\
\hline Turyk 2013 & 10 & 218 & 34 & 218 & $10.3 \%$ & $0.26[0.13,0.54]$ & & \\
\hline Woods 2012 & 22 & 283 & 145 & 283 & $12.1 \%$ & $0.08[0.05,0.13]$ & $\rightarrow$ & \\
\hline Total $(95 \% \mathrm{Cl})$ & & 3604 & & 3635 & $100.0 \%$ & $0.24[0.15,0.38]$ & & \\
\hline Total events & 217 & & 690 & & & & & \\
\hline \multirow{2}{*}{\multicolumn{7}{|c|}{$\begin{array}{l}\text { Heterogeneity: } \mathrm{Tau}^{2}=0.38 ; \mathrm{Chi}^{2}=50.10, \mathrm{df}=8(P<0.00001) ; I^{2}=84 \% \\
\text { Test for overall effect: } Z=6.20(P<0.00001)\end{array}$}} & $0.05 \quad 0.2$ & $\begin{array}{lll}1 & 5 & 20\end{array}$ \\
\hline & & & & & & & Favours intervention & Favours no intervention \\
\hline
\end{tabular}


well-controlled asthma (i.e., ACT score of 25) from 10 to $20 \% 2$ years after interventions [23] (Table 1).

Seven studies $[9,14-17,19,22]$ measured the use of short-acting asthma medications or bronchodilators (BD) e.g., $\beta-2$ agonists. Six $[9,14-16,19,22]$ reported a significant decrease in the number of patients needing these medications (Table 1). Meta-analysis on the four studies with complete data [14, 15, 17, 22] showed a significant reduction in need for short-acting asthma medications/BD with interventions $(\mathrm{OR}=0.28$; 95\% CI 0.16-0.51) (Fig. 7). Furthermore, use of AAP was also found to be significantly increased in five studies [14-16, $18,24]$ after interventions $(\mathrm{OR}=8.87$; 95\% CI 3.8520.45) (Fig. 8).

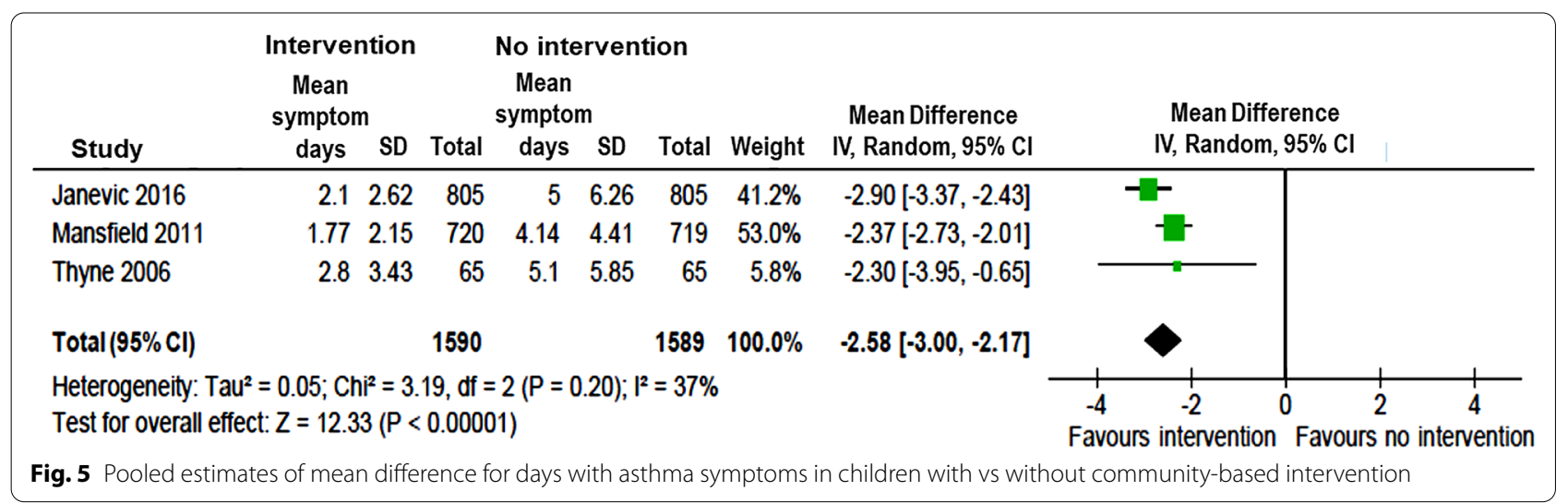

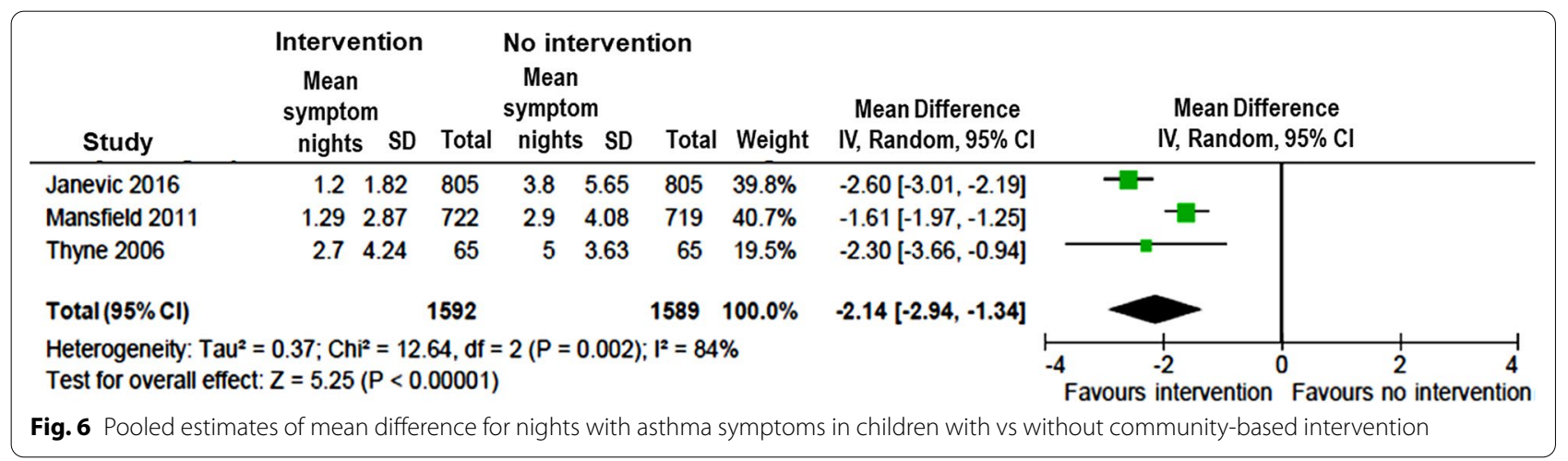

\begin{tabular}{|c|c|c|c|c|c|c|c|c|}
\hline \multirow[b]{2}{*}{ Study } & \multicolumn{2}{|c|}{ Intervention } & \multicolumn{3}{|c|}{ No intervention } & \multirow{2}{*}{$\begin{array}{l}\text { Odds Ratio } \\
\text { M-H, Random, } 95 \% \mathrm{Cl}\end{array}$} & \multirow{2}{*}{\multicolumn{2}{|c|}{$\begin{array}{c}\text { Odds Ratio } \\
\text { M-H, Random, } 95 \% \mathrm{Cl}\end{array}$}} \\
\hline & BD use & Total & BD use & Total & Weight & & & \\
\hline Fox 2007 & 33 & 280 & 118 & 280 & $25.0 \%$ & $0.18[0.12,0.28]$ & $\longrightarrow$ & \\
\hline Lara 2013 & 29 & 117 & 90 & 145 & $23.3 \%$ & $0.20[0.12,0.34]$ & & \\
\hline Lob 2011 & 49 & 484 & 149 & 484 & $26.2 \%$ & $0.25[0.18,0.36]$ & - & \\
\hline Rapp 2018 & 84 & 187 & 103 & 187 & $25.4 \%$ & $0.67[0.44,1.00]$ & & \\
\hline Total $(95 \% \mathrm{Cl})$ & & 1068 & & 1096 & $100.0 \%$ & $0.28[0.16,0.51]$ & - & \\
\hline Total events & 195 & & 460 & & & & & \\
\hline $\begin{array}{l}\text { Heterogeneity: } \\
\text { Test for overall }\end{array}$ & $\begin{array}{l}\text { 31; } \mathrm{Chi}^{2}= \\
=4.24(\mathrm{P}\end{array}$ & $\begin{array}{l}22.56, \mathrm{df} \\
<0.0001)\end{array}$ & $=3(P<0$. & .0001); & $I^{2}=87 \%$ & & $\begin{array}{lcc}0.1 & 0.2 & 0.5 \\
\text { Favours intervention }\end{array}$ & $\begin{array}{ccc}2 & 5 & 10 \\
\text { Favours no intervention }\end{array}$ \\
\hline \multicolumn{9}{|c|}{ BD = bronchodilator/short-acting asthma medication } \\
\hline \multicolumn{9}{|c|}{$\begin{array}{l}\text { Fig. } 7 \text { Pooled odds ratio (OR) of short-acting asthma medication/bronchodilator (BD) uses in children with vs without community-based } \\
\text { intervention }\end{array}$} \\
\hline
\end{tabular}




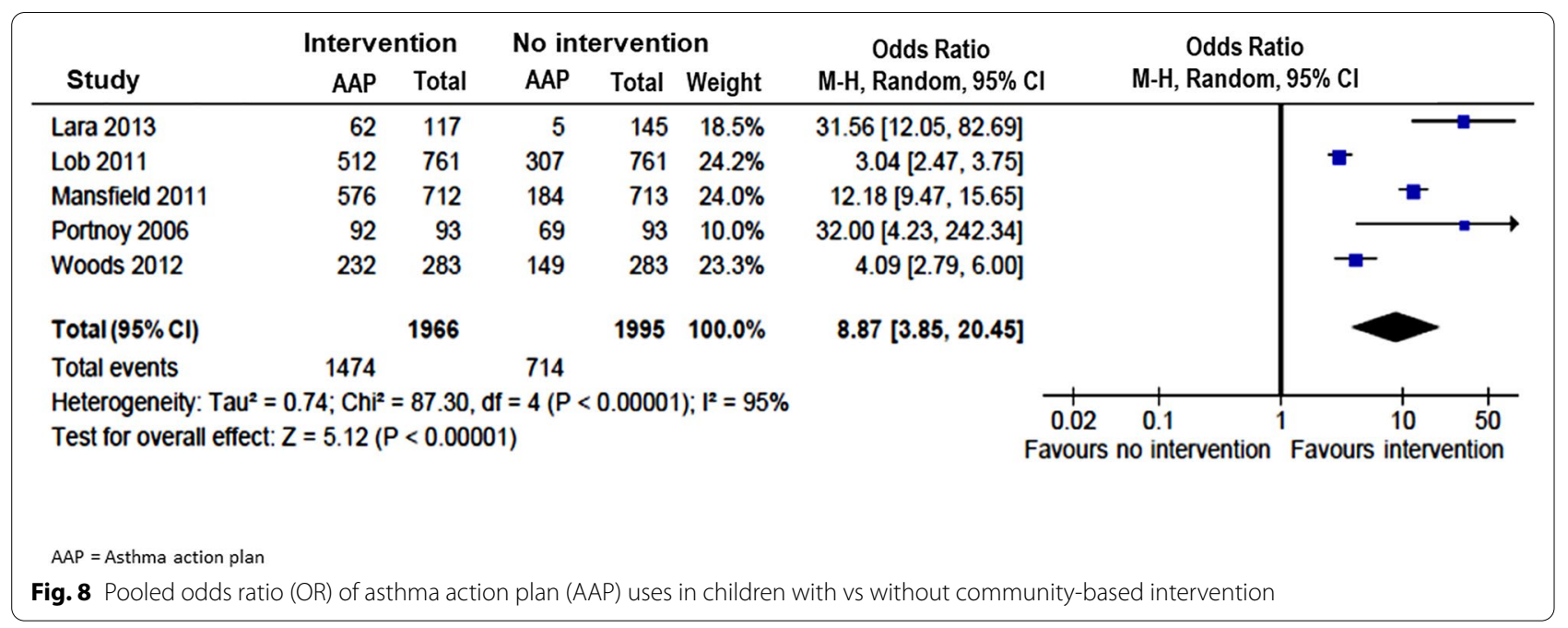

\section{Effect on other outcomes}

Use of long-acting/controller asthma medication was evaluated in four studies and was found to have increased by $12 \%$ to $127 \%(19,20,24,25)$ (Table 1$)$. Data on days missed from school were insufficient for meta-analysis. However, all the six studies $[15,16,18-20,26]$ that reported asthma-related school absenteeism found a significant reduction, ranging from 41 to $83 \%$. Three of these six studies $[15,18,26]$ also reported reduction (50$64 \%$ ) in days missed from work by parents/carers due to their child's asthma (Table 1).

\section{Discussion}

Our comprehensive systematic review and metaanalysis involving a total of 181,408 children with asthma has demonstrated that community-based asthma interventions with multiple components provided at various community settings can reduce health service use, improve asthma-related symptoms and potentially reduce school absence. We have identified that almost all (95\%) community-based multicomponent interventions included at least three main components i.e., selfmanagement asthma education, home environmental risk assessment and care coordination.

As asthma cannot be cured, focus of asthma management need to be placed in measures to achieve optimal asthma control and minimizing risk of severe complications. Like many other chronic illnesses, effective asthma management requires involvement of multiple stakeholders i.e. family, school, community and policy organizations or agencies, to support the patient's role as manager of his/her own health [30, 31]. In the Chronic Care Model (CCM), Wagner and colleagues [30] identified six elements (i.e. self-management support, community resource, decision support, delivery system design, organizational support, clinical information system) to overcome the deficiencies in chronic disease management such as poor adherence to practice guidelines, lack of care coordination and planned care, lack of active follow up and inadequate training for patients to manage their illness. Of the six elements of CCM, self-management is the key component which involves recognizing the patient's central role in managing their illness, and provide patients and families with support to acquire skills and confidence in managing their own health care [31]. This is of particular importance in asthma care as evident from our systematic review where education on basic asthma knowledge and self-management skills was one of the main core interventions. However, intervention program with only asthma education may not be adequate for achieving optimal asthma control. In a recent study of a community outreach program which focused on asthma education for Aboriginal children with asthma, the investigators had failed to find significant improvement in unscheduled medical visits and quality of life despite some improvement in carer's knowledge and skills about asthma [32]. A review conducted by Wu \& Takaro [33] demonstrated that a combination of interventions, involving both environmental measures for trigger reduction and education of self-management skills, was effective in improving clinical symptoms and acute service utilizations for asthmatic children, but such improvements were not observed in studies with asthma education as the only intervention. Several systematic reviews have also been conducted previously on educational programs for asthma self-management but the results were inconsistent [4, 34-36], suggesting 
that asthma education alone may not be sufficient for effective asthma management, especially for children.

Home visit and environmental trigger assessment is another commonly used interventions among studies included in this review. It is well-documented that asthma exacerbations are linked to indoor housing conditions and exposure to allergens such as inadequate ventilation, environmental tobacco smoke, pests etc. [37]. Home visitations provide an opportunity to assess and address potential environmental triggers that caused asthma exacerbation. Many studies have evaluated the impact of interventions targeting asthma triggers in the home environment. Although improvement in asthma symptoms and urgent care visits were consistently reported across the studies, level of asthma control and hospital admissions due to asthma were uncertain [38-40]. Furthermore, families receiving home-based interventions were often supplied with environmental remediation products (e.g. vacuum cleaners, bed coverings, pest abatements) to eliminate potential triggers in the home environment. It has been suggested that the provision of environmental remediation products may not provide additive benefit to asthma outcomes [41]. This is somewhat consistent with our findings. When comparing between studies with and without environmental remediation supplies, there was no additional improvement observed in both ED visits and hospitalizations associated with asthma [17, 21].

Care coordination is a crucial component in the effort to assist patients or families in navigating through health care or social systems. It facilitates interaction between patients/families and the health care providers, as well as linkage to social services to address family needs or problems. In all the asthma programs reviewed here, care coordination is one of the core interventions together with self-management education and home environmental assessment. The three reviewed studies $[12,16,20]$ that placed specific emphasis on care coordination consistently reported significant reduction in ED visits and hospital admissions, which is indicative of the importance of care coordination in improving health outcomes for children with asthma. However, whether care coordination alone is adequate to achieve effective asthma control has yet to be determined and should be the subject for future research investigations.

Apart from the core interventions (i.e., selfmanagement education, home environmental assessment and care coordination), most of the reviewed studies had their interventions extended to schools, primary practices, public/organizational agencies and the wider community to promote asthma awareness and support, as well as to advocate for more asthma-friendly environment or policy changes. Although nine studies had similar program designs that included all seven intervention elements (i.e. all three core components plus the involvement of schools, primary care providers, community campaigns, policy makers/organizations) [12, $15-17,20,21,29]$, there were great variations between the remaining 12 studies in regarding the components of their interventions. Therefore, it is not possible to clearly identify the optimal combination of intervention elements that had led to the improvement observed in the summary effects.

It was also worth noting that none of the studies included the use of telehealth care, which has drawn considerable attention in the recent pandemic outbreak. In general, telehealth refers to health services delivered by electronic communication media such as telephone, video or internet. It is effective in overcoming geographical barriers and has been shown to be costeffective in providing health advice and education for patients with chronic illnesses [42]. However, a recent systematic review of 21 RCTs using telehealth care (including text messaging, telephone, video conferencing etc.) did not show any significant improvement in quality of life or ED visits for patients with asthma [43]. More researches are needed to confirm the impact of telehealth on asthma management for children.

Several limitations of this review should be noted. There are few RCT studies available for community-based interventions with multiple components, in particular, for childhood asthma. We only identified one RCT in this review. Comparisons in our meta-analyses were made primarily between before and after intervention, which may lead to overestimation of the summary effect size. However, the effects of studied interventions were, in general, consistent and followed the same positive trend across the measured outcomes. In addition, in the six studies [9, 10, 19, 21, 28, 29] that included comparator groups, their findings were in agreement with that of the meta-analysis, with five out of the six studies $[9,10$, $19,28,29]$ reported greater improvements in asthma outcomes among intervention groups than the controls.

High level of heterogeneity was identified and was likely due to different study designs, settings and intervention components, as well as low number of studies included. In order to incorporate the between-study variations, random effect models were used to estimate the summary effect size. Also, we performed subgroup analyses to explore the heterogeneity amongst studies and our results showed little change to the direction or magnitude of the estimated effects. Meanwhile, with stepwise single-study elimination analysis, we did not observe significant change in the outcomes for which pooled effect sizes were calculated, suggesting that there was minimal publication bias. 
Although a considerable number of key words and search terms have been used, it is possible that we did not extract all the relevant articles in this review. Thus, in addition to electronic searches, we conducted hand search of reference lists to extract all relevant articles in the existing literatures. Most of the studies included were conducted in the US, with majority of the participants from ethnic minority background and low-income households. As healthcare system in US is very different from other countries, results of this review may not be generalizable. Finally, we included only articles written in English language and might have missed findings from studies published in other languages.

\section{Conclusion}

Asthma management in children is complex and requires coordinated efforts from a wide range of stakeholders. To enable effective disease management, it needs engagement of community and collaboration between families, schools, primary care providers and government/organizational agencies. As summarized by Clark et al. [44], a successful asthma program should be "community-centred", "clinically connected" and "continuously collaborative". Community-based asthma programs with comprehensive approach examined in the present review aligned with these guiding principles and could be an effective model of care in improving health outcomes and reducing acute care need for children with asthma.

\begin{abstract}
Abbreviations
CINAHL: Cumulative index to nursing and allied health literature; EMBASE: Exerpta Medica dataBASE; ED: Emergency department; AAP: Asthma action plan; RCT: Randomised controlled trial; OR: Odds ratio; MD: Mean difference; DALY: Disability adjusted life year; ACT: Asthma control test; FEV': Forced expiratory volume in one second; ROBINS-I: Risk of bias in non-randomised studies tool; CCM: Chronic care model.
\end{abstract}

\section{Acknowledgements}

Dr Nusrat Homaira is supported through Early Career Fellowship Scheme of the National Health and Medical Research Council of Australia (APP1158646). We also thank the UNSW library for assistance with electronic search.

\section{Authors' contributions}

$\mathrm{NH}$ conceptualized and designed the study, contributed to data analysis and interpretation, reviewed and revised the manuscript; MC conceptualized and designed the study, conducted literature review, data analysis and data interpretation, drafted the initial manuscript and revised the final manuscript; AJ participated in conceptualized the study, critically reviewed and revised the final manuscript; RL contributed to study design, provided research guidance and critically reviewed and revised the final manuscript; LO and SW contributed to study design, critically review and revised the final manuscript; MG and CB contributed to study design, assisted with literature review, critically reviewed and revised the final manuscript; and agree to be accountable for all aspects of the work. All authors read and approved the final manuscript.

\section{Funding}

This study was supported by the Rotary Club of Sydney Cove, Kids to Adult (K2A) Clinical Academic Group, SPHERE and Sydney Children's Hospital at Randwick.

\section{Availability of data and materials}

All data generated or analysed during this study are included in this published article.

Ethics approval and consent to participate

Not applicable.

\section{Competing interests}

The authors declare that they have no competing interests.

\section{Consent for publication}

Not applicable.

\section{Author details}

${ }^{1}$ Discipline of Paediatrics, School of Women's and Children's Health, Faculty of Medicine, University of New South Wales, Sydney, NSW 2031, Australia.

${ }^{2}$ Respiratory Department, Sydney Children's Hospital, Randwick NSW 2031, Australia.

Received: 17 September 2020 Accepted: 29 January 2021

Published online: 15 February 2021

\section{References}

1. Network TGA. The global asthma report 2018. Auckland: The Global Asthma Network; 2018.

2. Deloitte Access Economics. The hidden cost of asthma. Australia: Asthma Australia and National Asthma Council Australia; 2015.

3. Clark NM. Community-based approaches to controlling childhood asthma. Annu Rev Public Health. 2012;33:193-208.

4. Coffman JM, Cabana MD, Halpin HA, Yelin EH. Effects of asthma education on children's use of acute care services: a meta-analysis. Pediatrics. 2008;121(3):575-86.

5. Sterne JAC, Hernan MA, Reeves BC, Savovic J, Berkman ND, Viswanathan $M$, et al. ROBINS-I: a tool for assessing risk of bias in non-randomized studies of interventions. BMJ. 2016;355:i4919. https://doi.org/10.1136/ bmj.i4919.).

6. Cochrane handbook for systematic reviews of interventions. The Cochrane Collaboration. 2011. www.cochrane-handbook.org.

7. Chapter: Analysing data and undertaking meta-analyses. Cochrane. www.training.cochrane.org/handbook. Accessed 17 Feb 2020

8. Review Manager (RevMan) [Computer program]. Version 5.3. The Nordic Cochrane Centre.

9. Kennedy S, Bailey R, Jaffee K, Markus A, Gerstein M, Stevens DM, et al. Effectiveness of evidence-based asthma interventions. Pediatrics. 2017. https://doi.org/10.1542/peds.2016-4221.

10. Bird SR, Noronha M, Kurowski W, Orkin C, Sinnott H. Integrated care facilitation model reduces use of hospital resources by patients with pediatric asthma. J Healthc Qual. 2012;34(3):25-33.

11. Holder-Niles F, Haynes L, D'Couto H, Hehn RS, Graham DA, Wu AC, et al. Coordinated asthma program improves asthma outcomes in high-risk children. Clin Pediatr. 2017;56(10):934-41.

12. Janevic MR, Stoll S, Wilkin M, Song PX, Baptist A, Lara M, et al. Pediatric asthma care coordination in underserved communities: a quasiexperimental study. Am J Public Health. 2016;106(11):2012-8.

13. Kercsmar CM, Beck AF, Sauers-Ford H, Simmons J, Wiener B, Crosby L, et al. Association of an asthma improvement collaborative with health care utilization in medicaid-insured pediatric patients in an urban community. JAMA Pediatr. 2017;171(11):1072-80.

14. Lara M, Ramos-Valencia G, Gonzalez-Gavillan JA, Lopez-Malpica F, Morales-Reyes B, Marin H, et al. Reducing quality-of-care disparities in childhood asthma: La Red de Asma Infantil intervention in San Juan. Puerto Rico Pediatrics. 2013;131(Suppl 1):S26-37. 
15. Lob SH, Boer JH, Porter PG, Nunez D, Fox P. Promoting best-care practices in childhood asthma: quality improvement in community health centers. Pediatrics. 2011;128(1):20-8.

16. Mansfield C, Viswanathan M, Woodell C, Nourani V, Ohadike YU, Lesch $\mathrm{JK}$, et al. Outcomes from a cross-site evaluation of a comprehensive pediatric asthma initiative incorporating translation of evidence-based interventions. Health Promot Pract. 2011;12(6 Suppl 1):34S-51S.

17. Rapp Kl, Jack L Jr, Wilson C, Hayes SC, Post R, McKnight E, et al. Improving asthma-related outcomes among children participating in the head-off environmental asthma in Louisiana (HEAL). Phase II Study Health Promot Pract. 2018;19(2):233-9.

18. Woods ER, Bhaumik U, Sommer SJ, Ziniel SI, Kessler AJ, Chan E, et al. Community asthma initiative: evaluation of a quality improvement program for comprehensive asthma care. Pediatrics. 2012;129(3):465-72.

19. Dor A, Luo Q, Gerstein MT, Malveaux F, Mitchell H, Markus AR. Costeffectiveness of an evidence-based childhood asthma intervention in real-world primary care settings. J Ambul Care Manage. 2018;41(3):213-24.

20. Findley S, Rosenthal M, Bryant-Stephens T, Damitz M, Lara M, Mansfield C, et al. Community-based care coordination: practical applications for childhood asthma. Health Promot Pract. 2011;12(6 Suppl 1):52S-62S

21. Fisher EB, Strunk RC, Sussman LK, Sykes RK, Walker MS. Community organization to reduce the need for acute care for asthma among African American children in low-income neighborhoods: the Neighborhood Asthma Coalition. Pediatrics. 2004;114(1):116-23.

22. Fox P, Porter PG, Lob SH, Boer JH, Rocha DA, Adelson JW. Improving asthma-related health outcomes among low-income, multiethnic, school-aged children: results of a demonstration project that combined continuous quality improvement and community health worker strategies. Pediatrics. 2007;120(4):e902-11.

23. Britto MT, Vockell AL, Munafo JK, Schoettker PJ, Wimberg JA, Pruett R, et al. Improving outcomes for underserved adolescents with asthma. Pediatrics. 2014;133(2):e418-27.

24. Portnoy JM, Jennings D. Utilization patterns in an asthma intervention. Ann Allergy Asthma Immunol. 2006:97(1 Suppl 1):S25-30.

25. Thyne SM, Rising JP, Legion V, Love MB. The yes we can urban asthma partnership: a medical/social model for childhood asthma management. J Asthma. 2006;43(9):667-73.

26. Turyk M, Banda E, Chisum G, Weems D Jr, Liu Y, Damitz M, et al. A multifaceted community-based asthma intervention in Chicago: effects of trigger reduction and self-management education on asthma morbidity. J Asthma. 2013;50(7):729-36.

27. Krieger JW, Takaro TK, Song L, Weaver M. The Seattle-King county healthy homes project: a randomized, controlled trial of a community health worker intervention to decrease exposure to indoor asthma triggers. Am J Public Health. 2005;95(4):652-9.

28. Naar S, Ellis D, Cunningham P, Pennar AL, Lam P, Brownstein NC, et al. Comprehensive community-based intervention and asthma outcomes in African American adolescents. Pediatrics. 2018;142(4):e20173737.

29. Clark NM, Lachance LL, Benedict MB, Doctor LJ, Gilmore L, Kelly CS, et al. Improvements in health care use associated with community coalitions: long-term results of the allies against asthma initiative. Am J Public Health. 2013;103(6):1124-7.
30. Wagner EH. Chronic disease management: what will it take to improve care for chronic illness? Eff Clin Pract. 1998;1(1):2-4.

31. Bodenheimer T, Wagner EH, Grumbach K. Improving primary care for patients with chronic illness. JAMA. 2002;288(14):1775-9.

32. Valery PC, Masters IB, Taylor B, Laifoo Y, O'Rourke PK, Chang AB. An education intervention for childhood asthma by Aboriginal and Torres Strait Islander health workers: a randomised controlled trial. Med J Aust. 2010;192(10):574-9.

33. Wu F, Takaro TK. Childhood asthma and environmental interventions. Environ Health Perspect. 2007;115(6):971-5.

34. Bernard-Bonnin AC, Stachenko S, Bonin D, Charette C, Rousseau E. Selfmanagement teaching programs and morbidity of pediatric asthma: a meta-analysis. J Allergy Clin Immunol. 1995;95(1 Pt 1):34-41.

35. Harris K, Kneale D, Lasserson T, McDonald VM, Grigg J, Thomas J. School-based asthma self-management interventions for children and adolescents with asthma. Paediatr Respir Rev. 2019;31:40-2.

36. Guevara JP, Wolf FM, Grum CM, Clark NM. Effects of educational interventions for self management of asthma in children and adolescents: systematic review and meta-analysis. BMJ. 2003;326(7402):1308-9.

37. Kanchongkittiphon W, Mendell MJ, Gaffin JM, Wang G, Phipatanakul W. Indoor environmental exposures and exacerbation of asthma: an update to the 2000 review by the Institute of Medicine. Environ Health Perspect. 2015;123(1):6-20.

38. Campbell JD, Brooks M, Hosokawa P, Robinson J, Song L, Krieger J. Community health worker home visits for medicaid-enrolled children with asthma: effects on asthma outcomes and costs. Am J Public Health. 2015;105(11):2366-72.

39. Kearney GD, Johnson LC, Xu X, Balanay JA, Lamm KM, Allen DL. Eastern carolina asthma prevention program (ecapp): an environmental intervention study among rural and underserved children with asthma in Eastern North Carolina. Environ Health Insights. 2014;8:27-37.

40. Shani Z, Scott RG, Schofield LS, Johnson JH, Williams ER, Hampton J, et al. Effect of a home intervention program on pediatric asthma in an environmental justice community. Health Promot Pract. 2015;16(2):291-8.

41. Bryant-Stephens T, Li Y. Outcomes of a home-based environmental remediation for urban children with asthma. J Natl Med Assoc. 2008;100(3):306-16

42. Dixon P, Hollinghurst S, Edwards L, Thomas C, Gaunt D, Foster A, et al. Cost-effectiveness of telehealth for patients with raised cardiovascular disease risk: evidence from the Healthlines randomised controlled trial. BMJ Open. 2016;6(8):e012352.

43. McLean S, Chandler D, Nurmatov U, Liu J, Pagliari C, Car J, et al. Telehealthcare for asthma: a Cochrane review. CMAJ. 2011;183(11):E733-42.

44. Clark N, Lachance L, Milanovich AF, Stoll S, Awad DF. Characteristics of successful asthma programs. Public Health Rep. 2009;124(6):797-805.

\section{Publisher's Note}

Springer Nature remains neutral with regard to jurisdictional claims in published maps and institutional affiliations.

\footnotetext{
Ready to submit your research? Choose BMC and benefit from:

- fast, convenient online submission

- thorough peer review by experienced researchers in your field

- rapid publication on acceptance

- support for research data, including large and complex data types

- gold Open Access which fosters wider collaboration and increased citations

- maximum visibility for your research: over $100 \mathrm{M}$ website views per year
}

At $\mathrm{BMC}$, research is always in progress.

Learn more biomedcentral.com/submissions 